\title{
El paisaje mórbido
}

Por Carlos Ossa

¿Qué sociedad ha inventado la transición? ¿Cuál es el relato y el chantaje que ejerce para nombrarla? Las preguntas circulan por un cierto vacío histórico, pues de acuerdo a los discursos políticos y estadísticos de estos años, la transición no tiene pasado, o en su defecto nace como un puro presente divorciado de cualquier comarca que no sea ella misma. Esta autorreferencialidad, este mudo placer por la tautología hace de la comunicación una especie de técnica de la actualidad y del periodismo un discurso opaco, transido de biografías efímeras y de calamidades inútiles. Lo político y lo comunicacional "transitan" por el deshabitado pasillo de sus conveniencias y transforman el acontecimiento, la información o el recado en vigilancia: arman un país hecho a la medida de gendarmes, empresarios y asesores.

Las comunicaciones escoltan la saga del mercado, lo catalogan y -finalmente- lo trasvisten de modernización, hacen de su cuerpo un imperio paradigmático del presente. La información organiza la figura del adversario y lo exhibe imposibilitado (por incapacidad o resentimiento) de ocupar un espacio: así, se pueden construir "agendas" impertérritas que condenan todo exceso a silencio, censura y reprobación. Marcan un tiempo único idéntico a sí mismo, donde una sola voz habla en todas partes: es una neolengua del desarrollo, virtualizada y obsesiva excluyendo todo lo que deteriore el beneficio de su cálculo. Así, el periodismo parece pobre y mediocre y queda sin retrato la operación de fondo que realiza: volver a la modernización la vida cotidiana, al consumo la política y a la actualidad la historia.

La distancia crítica, entonces, cae en la trampa obsolescente de creer en la reforma lingüística del discurso periodístico, de diagnosticar un "problema" de formación y reclamar un "pasado" épico como soluciones. Discutir la superficie vencida de una piel inexistente, vivida y planteada como salvaguardia gremial. La operación del periodismo es más exultante, invisible y poderosa, sencillamente no dice nada (1), no tiene nada que decir. La política circula con sus "anomalías sin consecuencias" (Baudrillard), amenazando con entregar el informe de un secreto, jamás revelado, y las noticias son la espera de esa revelación. Hay un gesto elíptico inconfesable reuniendo fracciones para dar coherencia a la transición, una invención social y -de la mano de Michel Certeau-: "cada uno por su cuenta, espera del otro una garantía que de consistencia a su simulacro"(2). Nos hemos acostumbrado al secreto, a su circulación requerida y contagiosa, a las explicaciones de especialistas declamando frases cortas, inanes y frías en el recetario mediático de una normalización asistida.

El periodismo se transforma en un mapa sin geografía, marcando puntos invisibles, pauperizando su oficio con las copias discursivas prestadas por la ley, en suma, hablando como si fuera la transición y no su relato. Ahí radica su detención, su llegar a ninguna parte, pues clona el cuerpo de un pacto que niega al país y sólo lo requiere para el usufructo, la clemencia y el olvido. El periodismo de la transición firma el pacto por el cual queda sin habla y a cambio recibe una oferta "tecnológica" y "administrativa" de testigo y juez. Recibe también un final a poner de muletilla en todas las editoriales y orificios: no al pasado porque nos recuerda que no tenemos presente. Pero, suponer una misionalidad del periodismo, reclamar para él una tarea enjundiosa y noble, protectora y calificativa, sería reproducir el slogan manoseado de una identidad y un principio, exigirle ser lo que la sociedad no es.

La transición no acabó porque nunca fue, ocupando su forma se instaló un espectro jurídico, un "realismo" policial, cercando la corriente de las pasiones y reduciendo la urbe a tareas de entretención y consumo. La calle debía ser corregida y de ella ahuyentada toda pretensión de igualdad, lo democrático del relato periodístico, su celebración ciudadana, fue restringir lo público a aventura, delito y erotismo cínico. La anécdota conforma la sigilosa escritura de una práctica que todos piensan elemental por lo débil de su comentario y esa debilidad es el justo punto donde se ejerce el silencio, el silencio de la política. No es la comunicación, es la política arruinando lo público para sostener su mandato. 
La transición necesitaba un discurso nebuloso y ligero, residual y -al mismo tiempo- extensivo donde poner lo inservible, lo molesto o lo indefenso gracias a su fragmentación, un discurso capaz de visibilizar un país y negarlo en la muestra, finiquitar su delirio con diagramas excluyentes capaces de identificar el lugar de cada uno: la videopolítica, en Chile, es la mercantilización de la desdicha(3), la zozobra del sujeto que es socorrido después de su llamada medial por quienes ya no asisten "proyectos", sino "personas" y esta formalización tiene éxito, gracias, a la exasperación del caso.

La noticia es una repetición de una repetición, por ello se la puede recortar, aplicarle una economía del signo, hasta dar sólo el enunciado de un facticidad. Retorna, luego, interpretando la cicatriz de un suceso de "conmoción pública" donde la información se antropologiza en búsqueda de una etnografía blanda, de barrio y caída capaz de sostener "una tragedia personal" unos cuantos minutos, y, sin embargo, ello no reduce sólo a testimonios triviales la práctica informativa, también describe un lenguaje que ha desestabilizado los discursos normativos con una crónica pasajera y mítica, descriptiva y cultural, ciega y creativa. Las audiencias -tal vez- no buscan información y encuentran en reportajes y especiales periodísticos un tiempo ritual donde el incidente, lo habitual de su existencia, mitifica la idea de un orden inalterable y riguroso que cumple con rubricar a cualquiera para hacerlo visible.

El imaginario de la transición tendría un costado epifánico donde descansar de su escándalo y, además, una zona preferencial donde mostrarse como víctima de una república periodística caracterizada por la caída de la democracia en el sicariato televisivo. A su vez, a fin de mantener la confianza en la administración de lo "obvio", agrega una promesa: la espacialidad globalizadora que decora nuestras fracturas con los íconos de un progreso esperanzador y un porvenir desarrollista. Entonces se hace rápido confundir la autonomía del sujeto con la vida privada y el consumo y la democracia con la igualdad y la participación. De aquí emerge un relato hedonista y sicótico que hace de lo público un estorbo ante el despliegue de la individualidad empresarial y el gasto sin fiscalización, y culpa de "ineficiencia" a la situación de los derrotados. El periodismo se mezcla con la tecnología e informa de una nueva hazaña de individualidades que sujeta a lo exótico, emotivo o raro, materializa la travesía de la subjetividad a través del formato del testimonio, del accidente o la fortuna sistemática. No se trata de una acusación por lo velado, tampoco el descubrimiento de imposturas ideológicas ejerciendo la seducción del olvido, sería tan fácil un apocalipsis retórico, es más bien indicar una ruta de comprensión y alejarse de la nostalgia por lo que no ha sido.

El periodismo escrito y televisivo en Chile se ha manejado con el mecanismo del "pensamiento urgente" es decir, ha hecho de la contingencia una defensa fundamental evitando los repliegues o los giros amenazantes que supongan el retraso de la fluidez, el acuerdo y el rédito. Su único destino es parecerse a lo que narra, no importando la multiplicidad de ecos y sombras, la variedad de gemidos y delitos, pues todos remiten a un verosímil carcelario congratulado con su fuerza, kitsch y megalomanía económica. El periodismo, a pesar, del disfrute diario que realiza del grotesco y de los esfuerzos por construir una heteronomía de lo popular contrabandeada como identidad secular y grasienta, funciona al modo de una lengua constitucional, una breve y a ratos furibunda "razón de estado", legalizando el marco consociativo de la transición y el contenido de su pacto: la sobrerrepresentación de las minorías políticas y sociales(4).

\section{El foro de las máscaras}

La transición destruye lo público para salvar lo político, y ello requiere el fin de toda confrontación, la domesticación del argumento por la facticidad. Entonces, la política debe elaborar "metanarraciones" auspiciadas por la renovación globalizadora, el desarrollismo nómade y fiduciario y la reafirmación de una sociedad de clases, pero sin clases: individuos híbridos, gitanos del consumo, inscritos en la unidad de la modernización. La política parece perder su esfera y se desplaza por la programación mediática sin orden ni cláusulas, se vuelve intempestiva y coloquial, asume los lenguajes audiovisuales y renuncia a toda especialidad: se hace in-específica. Disolviendo su lenguaje en el gesto catódico y pulsional de la televisión(5), la política de la transición niega el espesor del poder, se deja sin lugar y se 
acomoda en la circulación infinita de un sistema de comunicaciones lleno de isotopías estéticas, mimetización de la impunidad, explicación judicial de los acontecimientos y desterritorialización de la cultura. De este modo, casi invisibilizada produce lo de siempre: poder.

Este rasgo habla de una forma de administrar lo actual, de dotarlo de una significación horizontal (no democrática) donde la transición es un plagio de las voces. El tema no es menor y la sensibilidad pública ya está habituada a leer las prácticas políticocomunicacionales como remanentes de operaciones visuales-publicitarias. Desde el retorno a la democracia, en Chile, la tendencia pareciera justificar las perspectivas más crepusculares, pues ni la libertad de expresión, ni la circulación diferenciada de ideas, ni las discusiones culturales pueden traspasar esa corteza escamosa de la repetición y la censura que caracteriza al mercado y la producción simbólica. El resultado parafraseando al pensador alemán Jeffrey Herf, sería la constitución de una sociedad desencajada entre su equipamiento tecnológico y su fundamentalismo moral, en suma, una experiencia de modernización reaccionaria.

Las explicaciones sobre la transición han sido escasas desde el espacio dramatúrgico, pues la tecnificación de los relatos con su arrogancia obesa excluyen cualquier dimensión no sujeta a la "estadística", son las nomenclaturas funcionarias de la democracia chilena las que defienden los repertorios modernizadores, a través, de la crónica sumisa de un orden depositado en el porvenir del lenguaje. Cuando semantizan los contenidos periodísticos estos repertorios no sólo tienen una influencia en lo dicho, además, la tienen en lo que se deja de decir. Al respecto, Guillermo Sunkel y Rafael Otano ofrecen algunos ejemplos:

"La autocensura tiene mucho que ver con el consenso generalizado y con el deseo de no molestar a nadie. El periodista se autocensura porque lesionar ciertos intereses o afectar algunas susceptibilidades le puede resultar muy caro. Si un inocente chiste sobre el Papa, contado por el humorista Palta Meléndez en el Festival de Viña, produjo la ira pública del entonces obispo de Valparaíso y del propietario de Megavisión, y si un simple garabato en pantalla del poeta showman Mauricio Redolés le apartó de la televisión definitivamente, es explicable que los profesionales se lo piensen antes de difundir informaciones o expresar ideas que puedan ofender a algunos poderes del país, que tienen la piel demasiado fina"(6).

Si las observaciones sobre el pensamiento reaccionario de Albert Hirschman, tipificado por una labia de la futilidad, la perversión y el riesgo, pudieran ser aplicadas a la lógica comunicacional de la transición, tal vez hallaríamos un dato recurrente: la intransigencia. Pero tales categorías, también pueden ser cuestionadas en la medida que ofrecerían un cuadro demasiado favorable a la crítica evidente y las apostillas de la queja y conclusiones sospechosamente- afines a las profecías autocumplidas. En todo caso, el tema de la intransigencia, permite comprender la discursividad política de la democracia actual. Hay una competencia semántica con un fuerte anhelo de realidad presionando sobre los medios de comunicación, y al mismo tiempo, éstos retroalimentándola a favor de un territorio sin densidades, pero exhuberante en superficies: la peritación(7).

Uno de los temas cruzados en este espacio es el de la memoria y el intento de reunir para un mismo tiempo lo quebrado, sin sepultura, perdido y hacerlo conciliable con la velocidad del capital, las relaciones corporativas y la tecnificación de las decisiones. El relato transicional debe entonces separar catástrofe de futuro, guerra de internet, ideología de globalización. Es toda la comunicación la exigida de gestión estratégica para lograr la espectacularidad de una imagen moderna, su reverberar en un mundo de protagonismos basados en la comunicación administrativa. Tal como lo indica Nelly Richard:

"La transición le encargó a los administradores oficiales del consenso la tarea de atenuar las marcas de la violencia que permanecía adherida al contorno de las palabras que nombran la conflictualidad del recuerdo, para reducir -eufemísticamente- la gravedad del sentido contenida en su dramática de los hechos y hacer que ya nada intolerable, nada insufrible, eche a perder las celebraciones oficiales de lo llevadero"(8). 
Eso explica, en parte, la renuncia a la llamada "política comunicacional", pues ésta obligaba al Estado a hacer la genealogía de la dictadura a la democracia, en cambio la privatización del sentido colectivo, le permitió hacer la genealogía de la política al mercado. No fue un asunto de pluralismo y desmalezamiento ideológico lo puesto en juego-como sugieren los epígonos de esta fórmula- fue la entrega de lo público a su mercantilización. Liberado el Estado de la función de comunicar, los asesores podían inventar los límites del realismo y las palabras contritas de la hazaña pacificadora, la unidad nacional y el fin de la disputa. A cambio la dimensión adversativa del periodismo se transformaba en intransitiva, en complemento neutro, un estado de las cosas que nunca se va y triunfa por indiferencia. Sin referencias e interpelado por la racionalidad técnica del sistema comunicacional el periodismo dibuja los trazos de un país circunscrito a un anhelo de riqueza y distinción reporteable y testificado por los cambios de la sociabilidad: el aumento en la compra de automóviles, la gordura de los chilenos, el crecimiento de los viajes al extranjero, la sexualidad oculta, la amenaza de la droga, la presencia internacional, etc.

La prensa no es -necesariamente- el sustituto de lo social en esta perspectiva, es más bien, un mecanismo de re-institucionalización de la vida cotidiana. Hace converger mundos y hablas dispares, escenifica sus vidas y las reemplaza terminada la brevedad de los testimonios. Al igual que la modernización manifestaría una lógica fabril de lo inesencial, pues su máquina semiótica no trabaja para la información lo hace en busca de una globalidad mediatizada que se imponga sobre los múltiples libretos de identidad. Es la creación de un paradestinatario temático y temporal: el consumidor. La tendencia no es nueva ni propia, atraviesa al mundo neoliberalizado en su afán de convertir a la política en la expresión de un target unidimensional. Una consecuencia sobre la fugacidad comunicacional y su pretensión de hiperactividad noticiosa es la confusión de la política con el espectáculo y ahí cabe resaltar el juicio de Eliseo Verón:

"La lógica del marketing es completamente incapaz de tratar tales objetos (el orden simbólico). No pueden construirse colectivos identitarios de largo plazo únicamente con imágenes ni únicamente con el orden indicial de la mirada característico de la televisión. Si el discurso político es un discurso en el que uno de los ejes es la construcción argumentativa de un proyecto, se trata pues de un discurso cualitativamente diferente del discurso unidimensional orientado a un blanco determinado, pues nunca es puramente persuasivo"(9).

La transición se pretendió persuasiva y política, se imaginó indicial y simbólica y sólo logró un esquema, un conjunto de instrucciones comunicacionales que no pueden contener a la llamada "ciudadanía", salvo la omitan, la retengan o la acusen, por eso la prensa no habla de ningún país y la política no llega a ser espectáculo, ya que no se ha alcanzado el punto de inflexión donde todo puede ser neutralizado bajo la convulsión del progreso. Cuando el orden se dispersa la transición renuncia al liberalismo informativo, se repliega y contrae para ejercer el dominio de la versión. La historia se camufla con el orador y sólo dos frentes se imponen como exigencia pública: oficialismo y oposición.

La racionalidad de la transición está unida a una forma y un imaginario del orden perenne y éste se desliza por la totalidad de lo social inundando de mensajes, isotipos y chauvinismos epocales el continente semántico de las advertencias, los informes y las noticias. Unas veces la "forma" se traduce en nacionalismo deportivo, a veces en sentimentalidad política o en confesionario de la vida privada. En ningún caso es un curso de acción deliberado y oscuro, resulta de la popularidad ascendente del drama, de los niveles diferenciados de información, de la continuidad de los avisadores o del reposicionamiento de lo público. Redactado en los márgenes de la sinceridad y la "imparcialidad" periodística(10) cree haber resuelto su implicación ideológica y estar inmunizado de la opinión corporativa: ¿qué puede narrar una lengua así constituida? ¿qué contextos invita y presenta como sociedad y nación? La matriz del gesto y la programación del evento. La funcionalidad comunicativa establece la relación entre el discurso político y los actores y los vincula con un foro restringido de audiencias y lenguajes, donde unos hablan y otros escuchan, unos deciden y otros esperan.

El periodismo teje los resultados de la transición a un verosímil que no se desvela por la desagregación social, al contrario es indiferente al espesor de tales mediaciones. Los 
públicos, entonces, son referidos a prácticas y debates de consulta callejera, opiniones telefónicas, encuestas y estados de ánimo. Lo noticioso deja de ser lo proyectual y se enfatiza lo confesional, generando un marketing de la presencia basado en historias seculares, diversiones comunes, aventuras normales posibles de ser vividas por cualquiera. La política sólo se preocupa de supervisar la dimensión contractual de las comunicaciones y exigir un "respeto" ecléctico entre las partes cuando se hace obligado hablar en público. Este funcionamiento es proclamado la "convivencia democrática" y alcanza -además- para explicar el nivel de madurez institucional. Genera también competencias técnicas y estratégicas relevando el papel de los relacionadores públicos, los especialistas en conflictos, los administradores de crisis, en suma, la elite preocupada de garantizar la libertad económica y su contacto con la globalización.

\section{El futuro ya fue}

En el tiempo global -paralelo, interactivo y desregulado- la masa monetaria circula en volúmenes y alucinaciones no medibles, pero incorpora a los discursos del desarrollo nacional la discusión de las oportunidades, la deslocalización y la creatividad financiera, sin embargo, estos impactos transnacionales no terminan en las casas de cambio, arriban a las ciudades, las vitrinas, las comidas y las imágenes, ya lo sabemos. Desde aquí, importa decir algo sobre el modo de construir la sociedad transicional: política de la pacificación, economía del riesgo, cultura de la no finalidad, comunicaciones de la paradoja. Ello nos permite advertir que muchos procesos ya no le pertenecen a esta sociedad, el imperio de las telecomunicaciones, las rutas de inversión, las histerias ciudadanas reclaman el "estilo internacional", la orfandad de las fronteras y la igualación visual y, como lo ha indicado Martin Hopenhayn:

"ocurre con los actos comunicativos lo mismo que con las inversiones financieras: no hay límite espacial ni demora temporal entre emisores y receptores de mensajes. Los flujos de la información y la circulación de imágenes en la nueva industria comunicativa son instantáneas y globalizadas. Esto imprime en quienes participan percepciones paradójicas. De una parte, sensación de protagonismo (...) De otra parte, sensación de anonimato (...) Para los que sólo acceden a la televisión y no a la pantalla del monitor (y que son la aplastante mayoría), el protagonismo creciente por la decodificación propia de los múltiples mensajes ajenos y, en contraste con ello, la conformidad con el hecho de que no serán nunca ellos quienes decidan sobre qué imágenes, qué textos y qué símbolos se imponen en el mercado cultural"(11).

La dinámica globalizadora exige a la transición corregir -permanentemente- su pacto, adaptarlo a la fuerza envolvente de un mercado comunicacional cuyos dispositivos escenifican un "futuro que ya fue". Hablamos de un salto al porvenir ya cumplido en la estrategia moderna de la cultura visual, en la nivelación del pasado y en la informatización del Estado como meta centenaria. De esta manera la tecnología permite a la política descolocar el lugar de lo social y a cambio proponer un sino real utópico: el neoliberalismo convertido en lenguaje de red, estructura virtual y resonancia privada apasionada con la ganancia.

La comunicación se abre a nuevos protocolos tecnológicos y la política -al margen de su afánse adscribe a la idea de una republicanización, pero sin actores sociales solo comunidades de interés, vecindarios de malestar resolviendo sus vidas en una edad local vacía. Los tiempos mixtos de la sociedad chilena con una obesidad comunicativa de efecto aleatorio sobre el consumo y la protesta difuminan ese cuerpo pasivo, delgado y solitario de la ciudadanía, inventada y convocada a realizar el futuro. La inclusión, el reconocimiento plástico, la celebración encerrada, el prestigio codificado se colocan de varas de sociabilidad, de medición de comportamientos y ejemplo de normalización y avance. Las relaturías comunicacionales se esmeran por disolver la cita territorial y expanden la visualidad -hacia un más allá- furtivo y provocador que parece más sostenible que el miedo a un presente que abandona, expulsa o cancela. Internet convertida en la épica del desarrollo nos restituye el país, pues podemos nacionalizar la globalización y vencer.

El periodismo ha construido una parte de esta sensibilidad insatisfecha con la inactualidad, el archivo o la militancia bienintencionada, pero inútil. Ha relativizado el tono controversial por un régimen de signos displicentes, sosegados y futiles, se ha distanciado del poder para 
servirlo mejor y ha pretendido ser algo que no existe: la transición. Por eso su escritura frágil, tibia e inexorable: "permite recodar lo que no fue y, a la vez, olvidar que lo recordado es falso".

1 Esto nos evita ser confundidos con frankfurtianos -pasando la cuenta- ansiosos por encontrar, muchos siglos después, la vieja máquina totalizante y su irreprimible teoría de la conspiración. No hay coaptación, no hay en rigor periodismo, sólo hay una sociedad imaginaria diluyéndose en su mentira.

2 LA INVENCIÓN DE LO COTIDIANO. Ediciones de la Universidad Iberoamericana. México 1996. Pág. 204.

3 La retórica del bienestar explica como "mala suerte" la caída de personas que narran su aflicción en programas televisivos o radiales, pues el país es rico y estable y la pobreza ya no se refiere a estructuras y decisiones, sino a voluntades y empeños. La televisión es el espacio donde se pide limosna y se ejercita una filantropía sin rostro. Alejado el peligro del contacto, el flujo no se detiene, y la televisión puede reunir -nuevamente- a la comunidad, a ella le habla y no a la sociedad.

4 Ver el artículo de RUIZ, Carlos: Democracia, Consenso y Memoria. Una reflexión sobre la experiencia chilena, en POLÍTICAS Y ESTÉTICAS DE LA MEMORIA. Compilado por Nelly Richard. Editorial Cuarto Propio, Santiago, agosto 2000. Pps. 15-22

5 No nos interesa ser identificados con las posiciones energúmenas de Bourdieu y Sartori sobre la televisión, y menos con la insistencia del mundo intelectual en definir sus puntos telefóbicos como el "tono" digno con el cual enfrentar la catástrofe de la futilidad mediática. La sumisión teledirigida de millones de "homo videns", encuentra su piedra de tope en una corriente de pensadores influidos por un cierto "elitismo residual" que los redime y convierte, al mismo tiempo, en los únicos escribas que no se han contaminado con la pesadilla de las masas. De esta suerte, descubren la comedia humillante que la televisión impone y pueden "desenmascarar" las manipulaciones informativas producidas por las corporaciones económicas, los lenguajes visuales y los impenitentes periodistas.

6 LA LIBERTAD DE LOS PERIOdistaS EN LOS MEDIOS. Documento de trabajo. Programa Libertad de Expresión. Escuela de Periodismo Universidad de Chile. Noviembre de 1999. Pps.11 y siguientes.

7 Aunque no es parte del tema central de este artículo, la peritación ocupa un estrado privilegiado en el campo de la demanda de investigación académica, se le encomienda elaborar los productos de un advertising global dirigiendo el saber hacia nuevas zonas de financiamiento que -reponen- de modo peligroso un empirismo a petición y encargo, sin contexto, arbitrio y responsabilidad mayor a la de su efecto económico.

8 RESIDUOS Y METÁFORAS. Ensayos de Crítica Cultural sobre el Chile de la Transición. Editorial Cuarto Propio, Santiago,. Junio de 1998. Pág. 30.

9 La Mediatización de lo Político, en COMUNICACión Y POLÍTICA. Editado por GAUTHIER, G; GOSSELIN, A. y MOUCHON, J. Editorial Gedisa, Barcelona 1998. Pág. 231.

10 La prensa defiende el prurito de la objetividad como una política del sentido y desde ella, después de tantas rebeliones epistemológicas contra la realidad, sigue fija a la idea de función social veraz. El periodismo pretende ser el lugar donde se lee y se mira la verdad. John Langer, dice sobre la materia algo interesante: "para explicar cómo las noticias pueden conseguir el consentimiento, al periodismo se la ha de tomar en serio respecto a su reivindicación de 'independencia'. La legitimidad depende de manera crucial del hecho de no ser visto recibiendo órdenes de los poderosos o transgrediendo conscientemente las noticias sobre el mundo para hacerlas cuadrar con los intereses creados o las definiciones dominantes (...) Cuando tienen lugar ciertos lapsus, éstos son debidos más a una excepción que a una norma. Desde este punto de vista resulta más sencillo observar como los presentadores proclaman de manera inconsciente que las noticias televisivas son, sencillamente, un 'espejo colocado frente a la realidad' que refleja los sucesos que tienen lugar". Los periodistas chilenos, en general, suelen escudarse en los mismos argumentos a la hora de tomar distancia con la institución política y se hacen agresivos con sujetos intermedios y elusivos con sujetos poderosos cuando los entrevistan o denuncian por televisión. LANGER, John: LA TELEVISIÓN SENSACIONALISTA. Editorial Paidós, Buenos Aires, 2000. Pág.32. 
11 Vida Insular en la Aldea Global, en Cultura y Globalización. Ediciones de la Universidad Nacional de Colombia. Facultad de Ciencias Sociales. Centro de Estudios Sociales. Bogotá, Julio 1999. Pág. 61. 